\title{
ФАКТОРНЫЙ АНАЛИЗ СЕЛЬХОЗУГОДИЙ РОССИИ
}

Мазуркин Петр Матвеевич

д-р техн. наук, проф., зав. кафедрой природообустройства и геодезии, Поволжский государственный технологический университет, Йошкар-Ола

E-mail: kaf_po@mail.ru

Михайлова Светлана Ивановна

канд. с.-х. наук, дои., доиент кафедры природообустройства и геодезии, Поволжский государственный технологический университет, Йошкар-Ола

\section{FACTOR ANALYSIS FARMLAND RUSSIA}

Mazurkin Peter Matveevich

Dr. Sc. Sciences, prof., Head. of the Department of Environmental Engineering and Geodesy, Volga State University of Technology, Yoshkar-Ola

Mihailova Svetlana Ivanovna cand. of agricult.l Sciences, Associate Professor, Department of Environmental Engineering and Geodesy, Volga State University of Technology, Yoshkar-Ola

Даны закономерности взаимного влияния и качества данных по площади сельхозугодий, пашни, сенокосов и пастбищ и залежи России за 1990-2012 гг.

Given patterns of mutual influence and the quality of data on the area of farmland, arable land, hayfields and pastures, and deposits of Russia (1990-2012 gg.)

Ключевые слова: сельхозугодия; факторный анализ; закономерности

Keywords: farmland; factor analysis; regularities

Введение. Время по годам является главным фактором, определяющим не только динамику состояния и использования земель (по исходным данным в [2]), но и позволяющим выявлять простые детерминированные закономерности взаимного влияния показателей. При этом само время исключается и это позволяет рассмотреть возможные бинарные отношения между показателями.

Вначале рассматриваются монарные отношения по ранговым распределениям значений у каждого фактора. Это дает рейтинг добротности измерений у множества показателей [1].

Цель статьи - на табличных данных [2] показать методологию факторного анализа сельскохозяйственных угодий (СХУ) Российской Федерации по динамике показателей за 1990-2012 гг.

Из-за короткого периода времени всего в 22 года динамики факторный анализ [1, 3-6] нами был проведен с применением только детерминированной общей закономерности в виде суммы двух биотехнических законов 


$$
y_{m}=y_{m 1}+y_{m 2}, y_{m 1}=a_{1} x^{a_{2}} \exp \left(-a_{3} x^{a_{4}}\right), y_{m 2}=a_{5} x^{a_{6}} \exp \left(-a_{7} x^{a_{8}}\right),
$$

где $y_{m}$ - тренд показателя, $x$ - объясняющая переменная, $a_{1} \ldots a_{8}$ - параметры модели (1), получаемые в CurveExpert (URL: http://www.curveexpert.net/).

Для выявления волновых членов необходимы ряды с 1961 года.

Исходные данные. Табличные данные за 2012 год [2] даны в таблице 1.

Таблица Ошибка! Текст указанного стиля в документе отсутствует.. Факторный анализ сельскохозяйственных угодий в границах Российской Федерации за период с 1990 по 2012 год (с землями личного пользования), млн. га

\begin{tabular}{|c|c|c|c|c|c|c|c|c|c|c|}
\hline \multirow[b]{2}{*}{ Год } & \multicolumn{2}{|c|}{ Сельхозугодия } & \multicolumn{6}{|c|}{ в том числе: } & \multirow[b]{2}{*}{$\begin{array}{l}\text { Сумма } \\
\text { рангов }\end{array}$} & \multirow{2}{*}{$\begin{array}{c}\text { Место } \\
\text { года }\end{array}$} \\
\hline & $R_{C X Y}$ & $S_{C X Y} \downarrow$ & $R_{\Pi}$ & $\begin{array}{c}\text { пашня } \\
S_{\Pi} \downarrow\end{array}$ & $R_{C \Pi}$ & $\begin{array}{c}\text { сенокосы } \\
\text { и пастб. } S_{C I} \uparrow\end{array}$ & $R_{3}$ & $\begin{array}{c}\text { залежь } \\
S_{3} \downarrow\end{array}$ & & \\
\hline 1990 & 21 & 222.4092 & 22 & 132.3042 & 21 & 87.8995 & 0 & 0.3472 & 64 & 19 \\
\hline 1991 & 20 & 222.4079 & 21 & 132.0687 & 22 & 86.8602 & & 0.3747 & 64 & 19 \\
\hline 1992 & 22 & 222.4863 & 20 & 132.0046 & 19 & 88.0811 & 2 & 0.3934 & 63 & 18 \\
\hline 1993 & 19 & 222.1220 & 19 & 131.5873 & 17 & 88.2488 & 3 & 0.4812 & 58 & 16 \\
\hline 1994 & 17 & 221.7946 & 18 & 130.6562 & 20 & 88.0124 & 4 & 1.0978 & 59 & 17 \\
\hline 1995 & 18 & 221.9852 & 17 & 130.1976 & 18 & 88.2292 & 5 & 1.4564 & 58 & 16 \\
\hline 1996 & 16 & 221.6342 & 16 & 128.8709 & 16 & 88.7830 & 6 & 2.0031 & 54 & 15 \\
\hline 1997 & 15 & 221.4916 & 15 & 127.8228 & 15 & 89.2209 & 7 & 2.5019 & 52 & 14 \\
\hline 1998 & 14 & 221.1618 & 14 & 126.4886 & 14 & 89.9438 & 8 & 2.8746 & 50 & 13 \\
\hline 1999 & 13 & 221.1513 & 13 & 125.3319 & 13 & 90.5856 & 9 & 3.3608 & 48 & 12 \\
\hline 2000 & 12 & 221.0888 & 12 & 124.3738 & 12 & 90.9234 & 10 & 3.9272 & 46 & 11 \\
\hline 2001 & 11 & 221.0036 & 11 & 123.8596 & 11 & 91.1430 & 11 & 4.1433 & 44 & 10 \\
\hline 2002 & 10 & 220.8962 & 10 & 123.4644 & 10 & 91.3514 & 12 & 4.2450 & 42 & 9 \\
\hline 2003 & 9 & 220.8326 & 9 & 122.5584 & 9 & 91.9036 & 13 & 4.5563 & 40 & 8 \\
\hline 2004 & 8 & 220.7297 & 8 & 122.1460 & 7 & 92.0237 & 14 & 4.7502 & 37 & 7 \\
\hline 2005 & 7 & 220.6790 & 7 & 121.7809 & 1 & 92.0988 & 19 & 4.9989 & 34 & 6 \\
\hline 2006 & 6 & 220.6327 & 4 & 121.5739 & 0 & 92.1171 & 22 & 5.1443 & 32 & 4 \\
\hline 2007 & 5 & 220.5679 & 3 & 121.5735 & 2 & 92.0945 & 21 & 5.1057 & 31 & 3 \\
\hline 2008 & 4 & 220.4916 & 6 & 121.6489 & 5 & 92.0520 & 18 & 4.9980 & 33 & 5 \\
\hline 2009 & 3 & 220.4616 & 5 & 121.6487 & 4 & 92.0530 & 16 & 4.9652 & 28 & 2 \\
\hline 2010 & 2 & 220.3963 & 0 & 121.4339 & 3 & 92.0595 & 20 & 5.1033 & 25 & 1 \\
\hline 2011 & 1 & 220.2721 & 1 & 121.4449 & 6 & 92.0283 & 17 & 4.9969 & 25 & 1 \\
\hline 2012 & 0 & 220.2208 & 2 & 121.4596 & 8 & 91.9967 & 15 & 4.9602 & 25 & 1 \\
\hline
\end{tabular}

В таблице 1 проведено ранжирование каждого фактора по предпорядку предпочтительности по вектору «лучше $\rightarrow$ хуже». Для сопоставимости чисел в факторном анализе размерность была изменена с тыс. га на млн. га.

Методика факторного анализа. У любых факторов имеется четкая векторная ориентация. Любой человек понимает направленность количественных изменений в сельском хозяйстве. Каждый человек стремится к лучшему в жизни, поэтому возможны всего два варианта векторов поведения [1, 3-6]: 
а) лучше меньше (да лучше, символ $\downarrow$ по вектору «лучше $\rightarrow$ хуже»);

б) лучше больше (и это благо, поэтому в таблице 1 символ $\uparrow$ ).

В функции $=\mathrm{PAHГ}(\mathrm{B} 1 ; \mathrm{B} \$ 1: \mathrm{B} \$ 23 ; 1)$ для первого показателя $S_{C X Y} \downarrow$ в программной среде Excel приняты следующие условные обозначения: В1 - идентификатор ранжируемого второго столбца и первой строки; В\$1 - первая строка ранжируемого столбца; В $\$ 23$ - последняя строка ранжируемого столбца по данным таблицы $1 ; 0 \vee 1$ - ранжирование по убыванию (0) или возрастанию (1). Ранги изменяются от нуля, поэтому придется из результатов ранжирования в программной среде Excel вычитать единицу (см. табл. 1).

Приведение всех показателей к вектору «лучше $\rightarrow$ хуже» дает возможность суммирования всех рангов и по их сумме снова провести рейтинг. Из данных таблицы 1 видно, что с экологических позиций самыми лучшими годами стали 2010-2012 гг. Именно в этот период сельхозугодия менее напряжены.

Взаимосвязь фактора от самого себя определяется ранговым распределением, то есть это - монарное отношение. Оно показывает добротность исходных данных и служит для проверки их достоверности и добротности по коэффициенту корреляции $R$ распределений $y=f(R=0,1,2,3, \ldots)$. Ранги удобно использовать вместо факторов, так как снимают математическую проблему «проклятия размерности», например, при рейтинге показателей.

Таким образом, факторный анализ проводится в четыре этапа:

1) выявление закономерностей рангового распределения;

2) рейтинг строк и столбцов матрицы по данным таблицы 1 ;

3) выявление закономерностей бинарных отношений;

4) рейтинг бинарных отношений по коэффициенту корреляции.

Ранговые распределения. Площадь СХУ (рис. 1) изменяется по формуле

$$
S_{C X Y}=220,33326 \exp \left(4,67711 \cdot 10^{-5} R_{C X Y}^{1,74251}\right) .
$$

Сравнение с данными таблицы 1 показывает, что в 2011 и 2012 годах фактическая площадь СХУ в России даже стала меньше среднестатистического значения по формуле (2), равного 220.33326 млн. га. Не увеличивать площади 
СХУ, а заняться по опыту США (с 1960 г.) и Китая (с 1970 г.) интенсификацией сельского хозяйства достижением оптимальной лесистости [5].

Площадь пашни от ранга (рис. 1) распределяется по закону Вейбулла

$$
S_{\Pi}=9956,9374-9836,0124 \exp \left(-3,883496 \cdot 10^{-6} R_{\Pi}^{1,88850}\right) .
$$

Закон Вейбулла показывает достижимость до предела максимума 9956, 9374 млн. га. Теоретически человек сможет распахать только 1709,8246 млн. га [2], то есть территорию всей нашей страны.
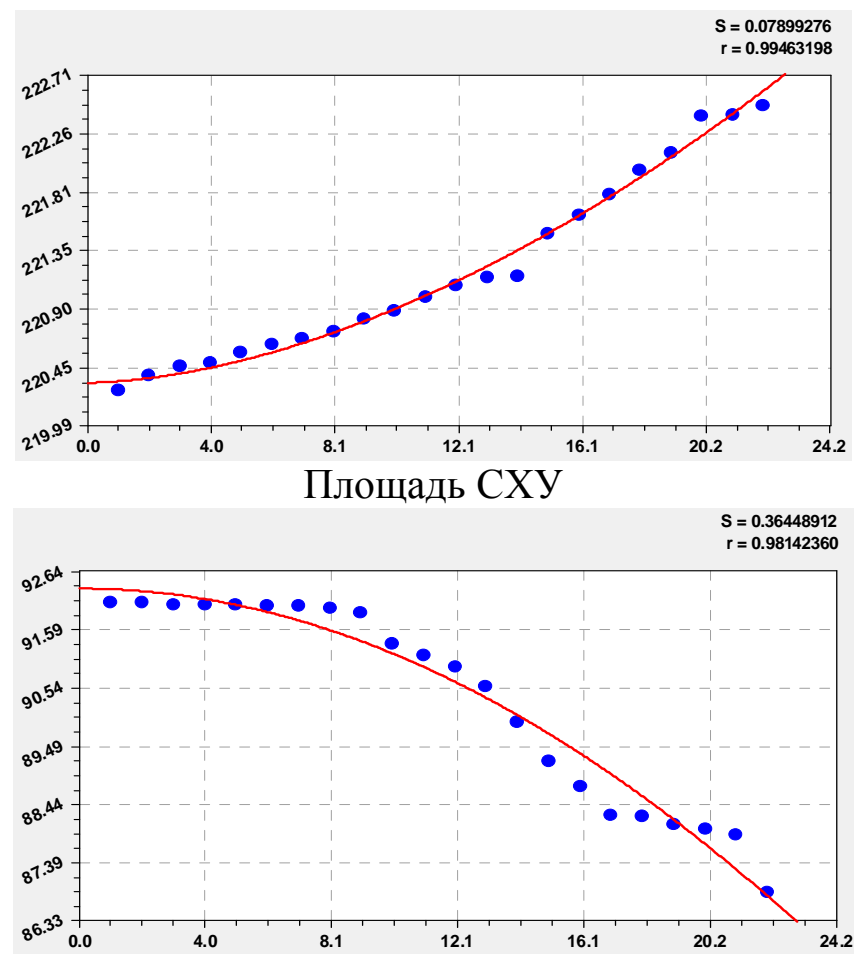

Площадь сенокосов и пастбищ

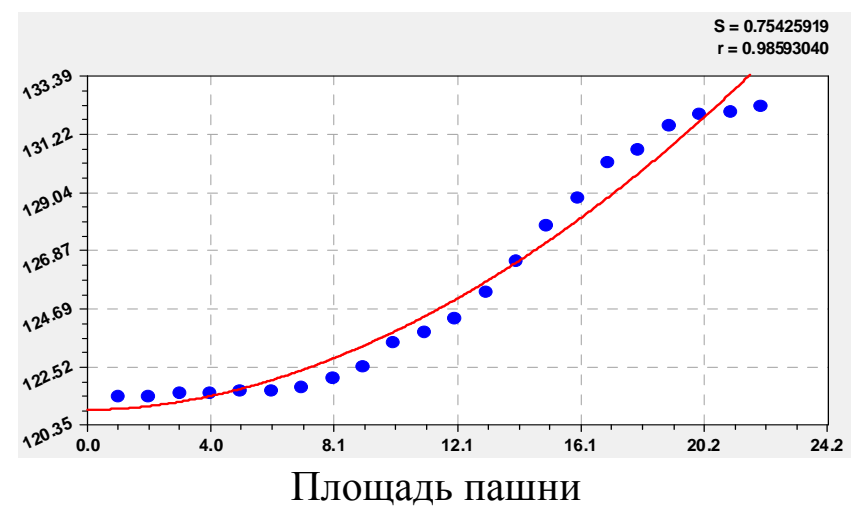

$S=0.08611320$

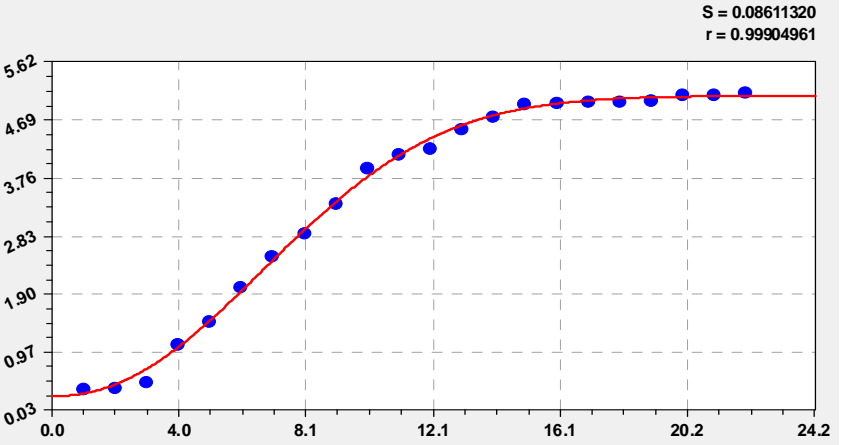

Площадь залежи

Рисунок 1. Графики ранговых распределений факторов земель России, млн. га

Площадь сенокосов и пастбищ (рис. 1) по рангам распределяется так:

$$
S_{C \Pi}=92,333320 \exp \left(-0,00012576 R_{C \Pi}^{2,00603}\right) .
$$

По закону экспоненциальной гибели фактическое максимальное значение площади сенокосов и пастбищ было в 2006 г. Это - стихийное поведение в России, неосознанность необходимости повышения травяного покрова (первый класс почвенного покрова по глобальному агроэкологическому зонированию).

Площадь залежи (рис. 1) изменяется по закону распределения Вейбулла

$$
S_{3}=5,08325-4,82183 \exp \left(-0,0085951 R_{3}^{2,18337}\right) .
$$

Фактическая площадь залежи в 5,1033 млн. га, больший предела достижимости по формуле (4) в 5,08325 млн. га, был в 2010 году. 
Ранжируем распределения по убыванию коэффициента корреляции:

1) динамика залежи при коэффициенте корреляции 0,9990;

2) изменение площади СХУ с коэффициентом корреляции 0,9946;

3) площадь пашни с адекватностью формулы (3) при 0,9859;

4) площадь сенокосов и пастбищ при тесноте факторной связи 0,9814.

Таким образом, специалисты обращают внимания на добротность данных по площади залежи, и меньше внимания на площадь сенокосов и пастбищ.

Бинарные отношения. Из-за короткого периода измерений в 22 года парные отношения определились линейным уравнением вида

$$
y_{m}=a_{1} x^{a_{2}=0} \exp \left(-a_{3}=0 x^{a_{4}=0}\right)+a_{5} x^{a_{6}=1} \exp \left(-a_{7}=0 x^{a_{8}=0}\right),
$$

или в виде простого линейного уравнения $y_{m}=a_{1}+a_{5} x$.

По этим отношениям получены следующие уравнения:

- влияния площади СХУ (рис. 2) на другие факторы

$$
\begin{gathered}
S_{\Pi}=-1125,4480+5,65600 S_{C X Y} ; \\
S_{C \Pi}=620,74981-2,39782 S_{C X Y} ; \\
S_{3}=549,31738-2,46859 S_{C X Y} ;
\end{gathered}
$$

- влияния площади пашни (рис. 3) на другие факторы

$$
\begin{gathered}
S_{C X \mathrm{~V}}=199,78574+0,17041 S_{\Pi} ; \\
S_{C \Pi}=144,10081-0,42775 S_{\Pi} ; \\
S_{3}=58,20258-0,43719 S_{\Pi} ;
\end{gathered}
$$

- влияния площади сенокосов и пастбищ (рис. 4) на другие факторы

$$
\begin{gathered}
S_{C X Y}=256,17779-0,38716 S_{C \Pi} ; \\
S_{\Pi}=332,76846-2,29233 S_{C \Pi} ; \\
S_{3}=-87,10057+1,00019 S_{C \Pi} ;
\end{gathered}
$$

- влияния площади залежи (рис. 5) на другие факторы

$$
\begin{gathered}
S_{C X У}=222,46567-0,38798 S_{3} ; \\
S_{\Pi}=133,10533-2,28064 S_{3} ; \\
S_{C I}=87,17182+0,97359 S_{3} .
\end{gathered}
$$



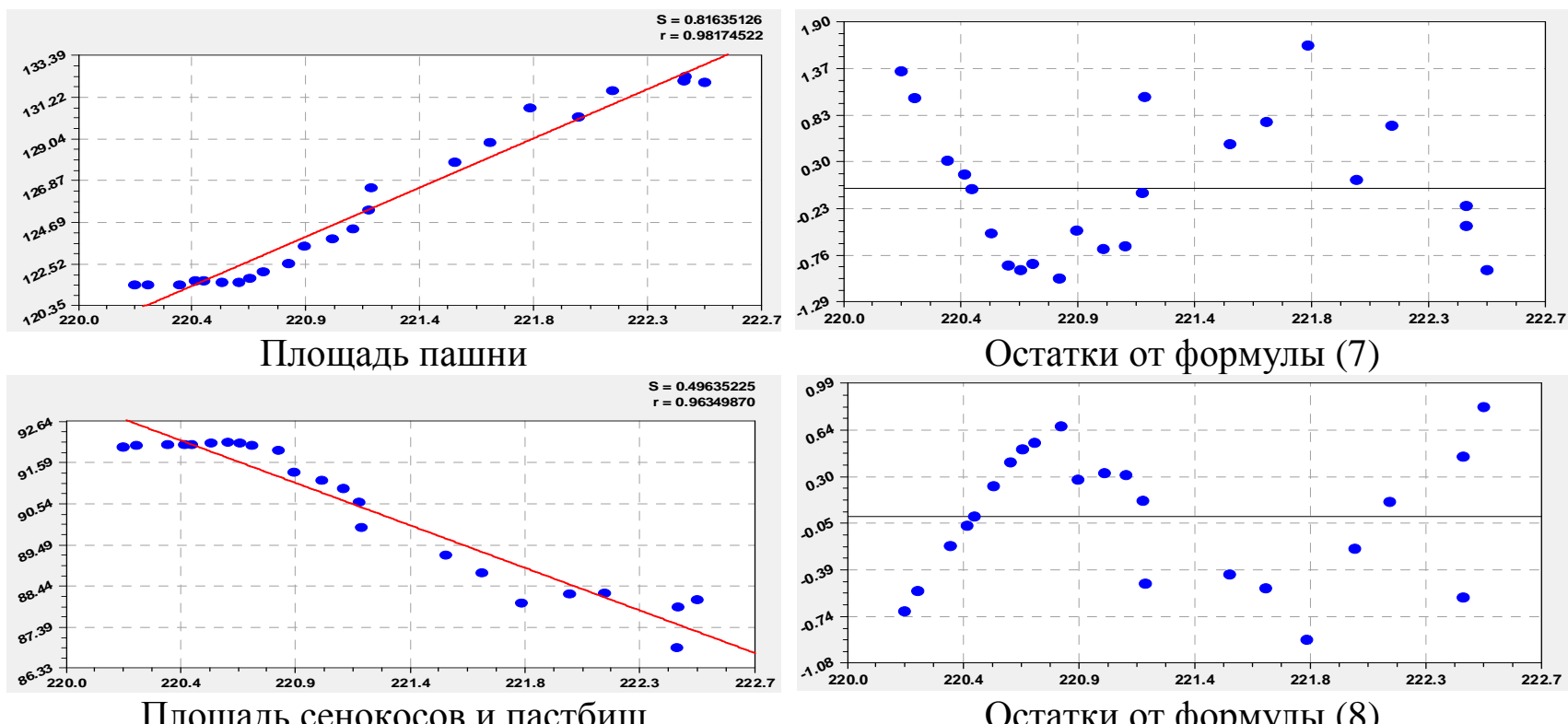

Площадь сенокосов и пастбищ

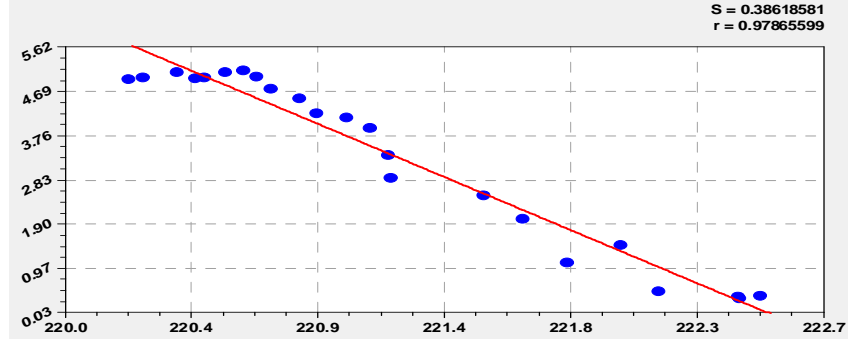

Площадь залежи

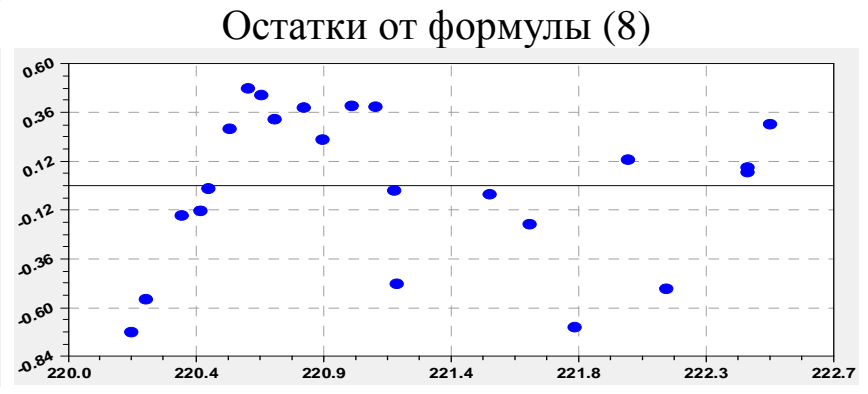

Остатки от формулы (9)

Рисунок 2. Графики влияния площади СХУ на другие земли России, млн. га
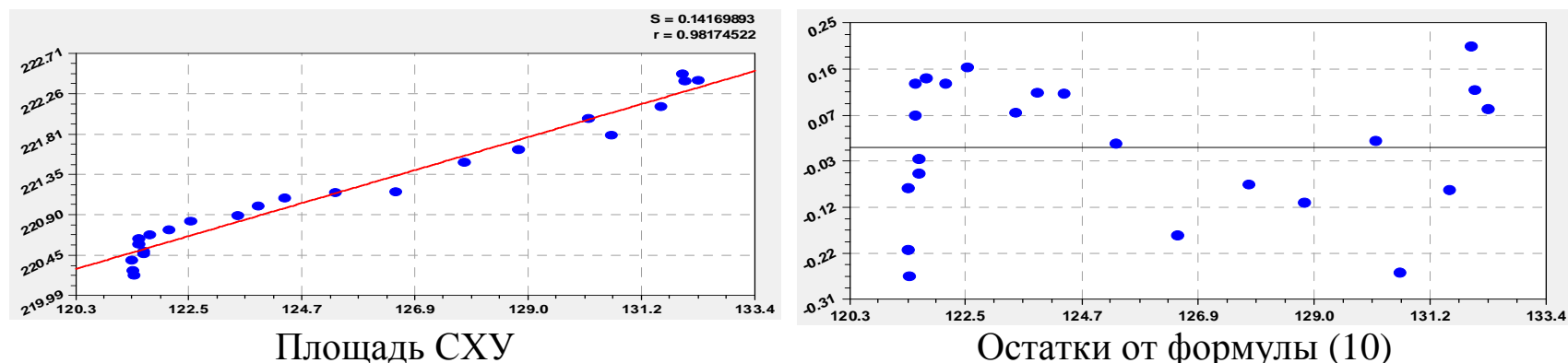

Площадь СХУ

Остатки от формулы (10)

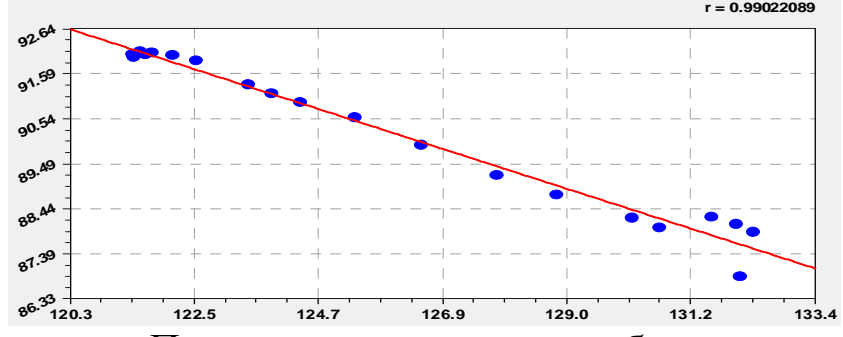

Площадь сенокосов и пастбищ

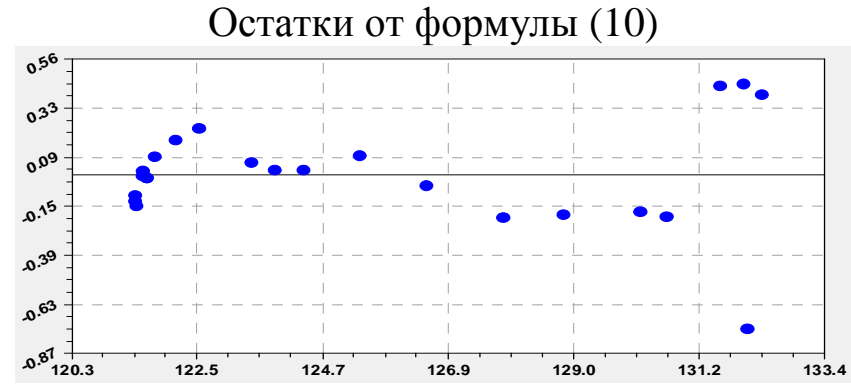

Остатки от формулы (11)
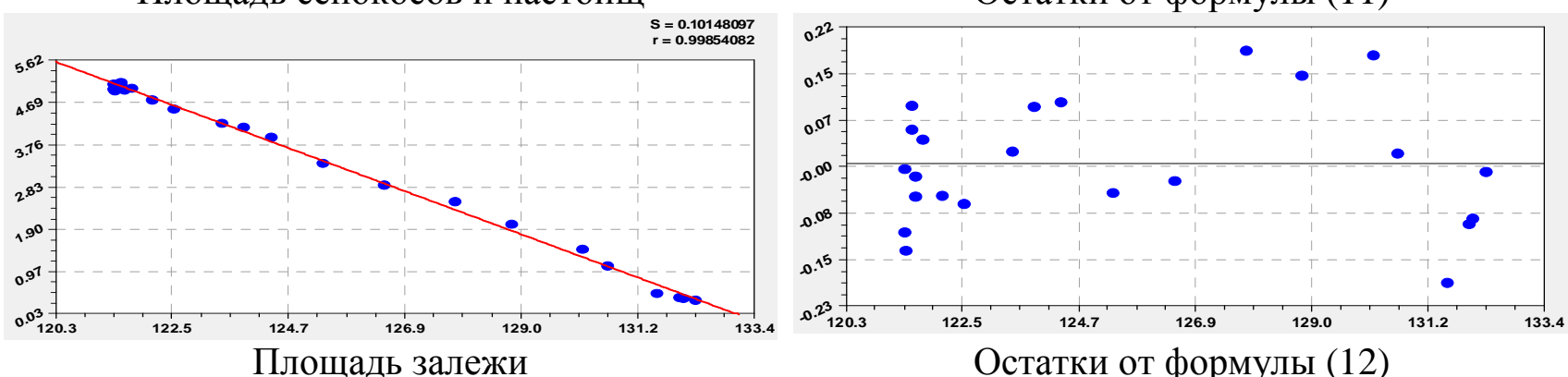

Рисунок 3. Графики влияния площади пашни на другие земли России, млн. га 

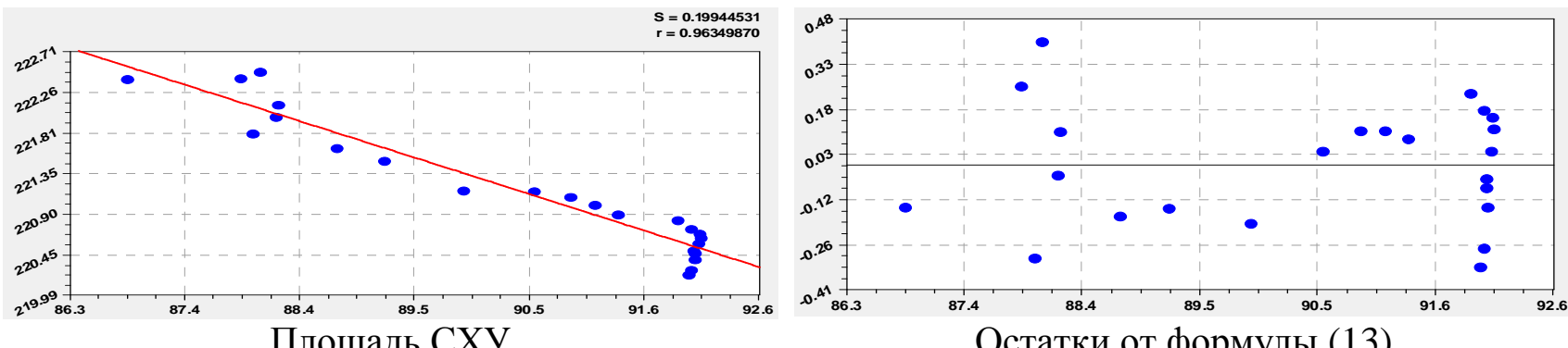

Площадь СХУ

Остатки от формулы (13)

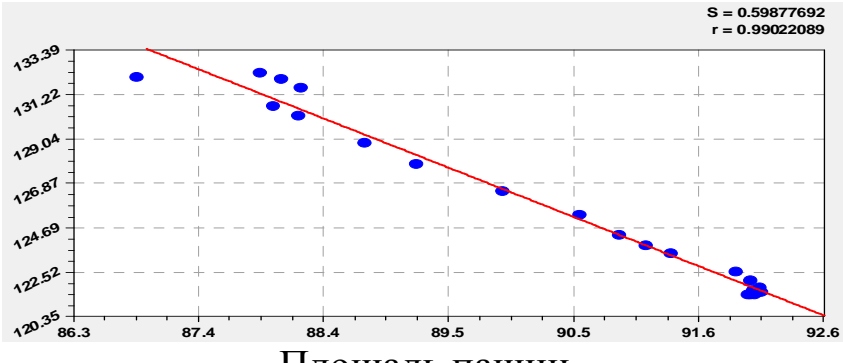

Площадь пашни

$\begin{aligned} S & =0.30433828 \\ r & =0.98679881\end{aligned}$

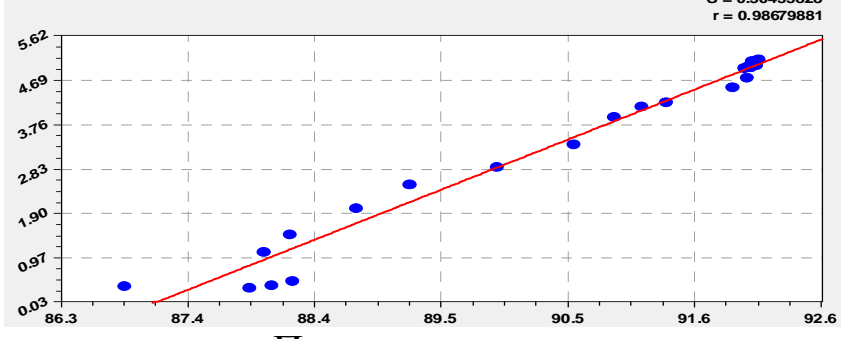

Площадь залежи

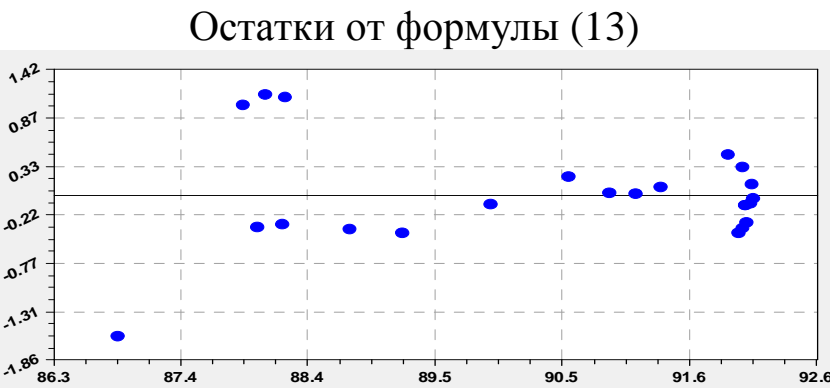

Остатки от формулы (14)

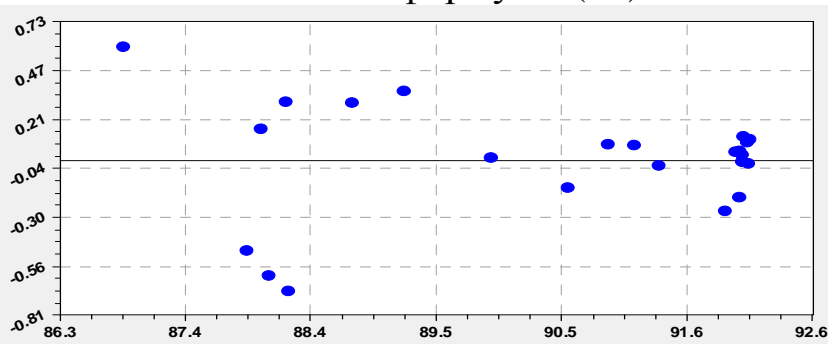

Остатки от формулы (15)

Рисунок 4. Графики влияния площади сенокосов и пастбищ на другие земли, млн. га
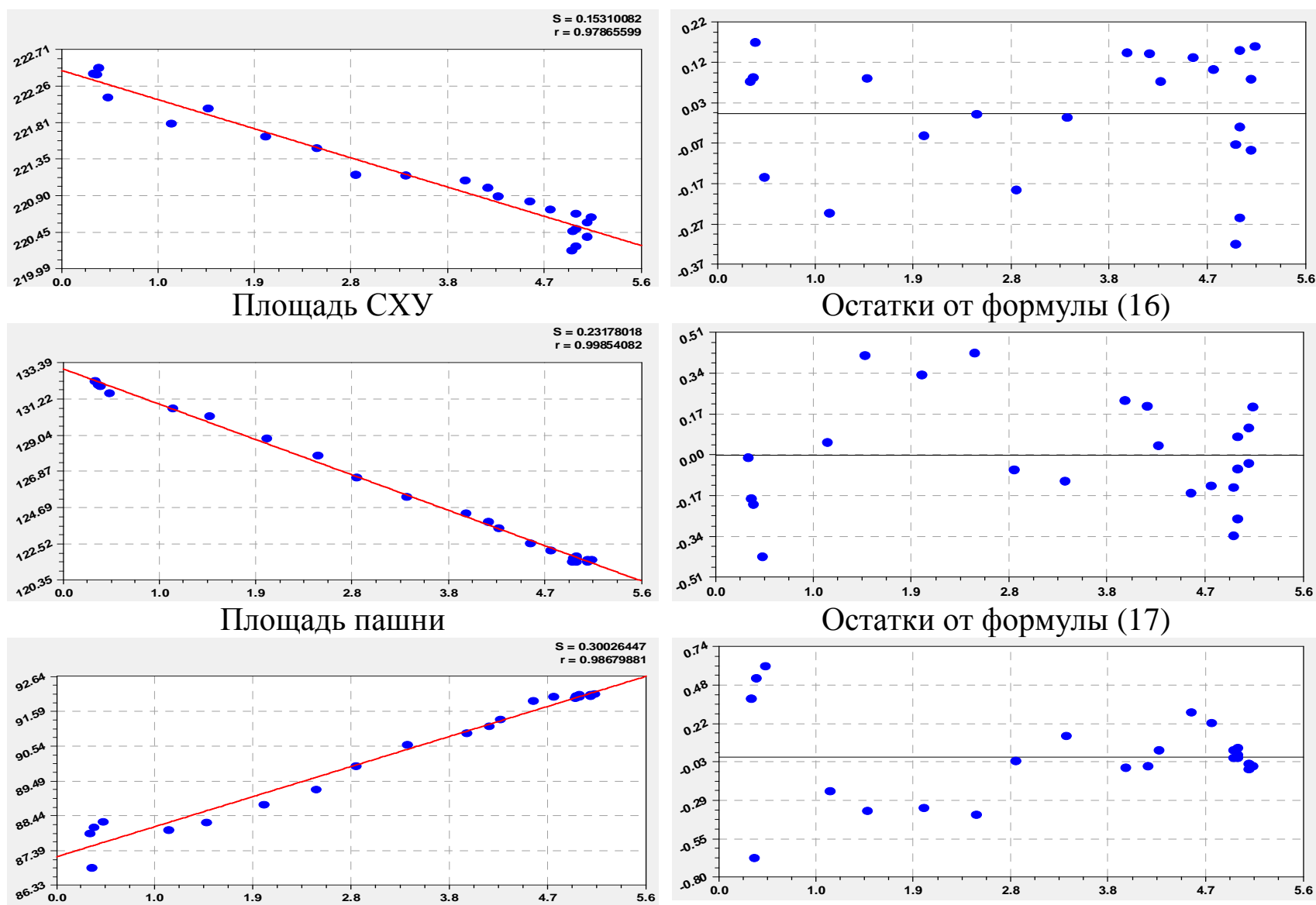

Площадь сенокосов и пастбищ

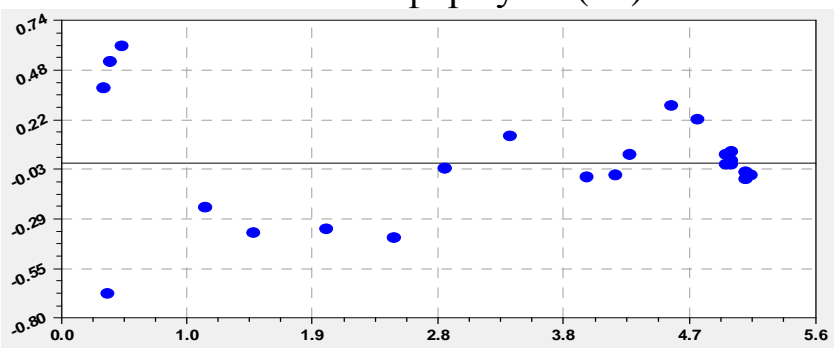

Остатки от формулы (18)

Рисунок 5. Графики влияния площади залежи на другие земли России, млн. га 
Из остатков видно, что между факторами существует колебательное возмущение. Если бы динамика СХУ и подкатегорий была бы с 1961 г. (данные FAO OOH по всем странам), то и тренды были бы нелинейными моделями.

Рейтинг бинарных отношений. В таблице 2 показан рейтинг ранговых и бинарных отношений между факторами из таблицы 1.

Таблица 2.

Корреляционная матрица и рейтинг факторов по детерминированным моделям

\begin{tabular}{|c|c|c|c|c|c|c|}
\hline \multirow{2}{*}{$\begin{array}{c}\text { Факторы } \\
\text { как объясняющие } \\
\text { переменные } x\end{array}$} & \multicolumn{4}{|c|}{ Факторы - показатели $y$, млн. га } & \multirow{2}{*}{\begin{tabular}{|c|} 
Сумма \\
коэффиц. \\
корреляции
\end{tabular}} & \multirow{2}{*}{$\begin{array}{c}\text { Рейтинг } \\
\text { влияющих } \\
\text { переменных }\end{array}$} \\
\hline & $S_{C X Y}$ & $S_{\Pi}$ & $S_{C \Pi}$ & $S_{3}$ & & \\
\hline Сельхозугодия $S_{C X y}$ & 0,9946 & 0,9817 & 0,9635 & 0,9787 & 3,9185 & \\
\hline Пашни $S_{\Pi}$ & 0,9817 & 0,9859 & 0,9902 & 0,9985 & 3,9563 & 2 \\
\hline Сенокосы и пастбища $S_{C I}$ & 0,9635 & 0,9902 & 0,9814 & 0,9868 & 3,9219 & 3 \\
\hline Залежи $S_{3}$ & 0,9787 & 0,9985 & 0,9868 & 0,9990 & 3,9630 & 1 \\
\hline Сумма коэффиц. коррел. & 3,9185 & 3,9563 & 3,9219 & 3,9630 & 15,7597 & - \\
\hline Рейтинг показателей & 4 & 2 & 3 & 1 & - & \\
\hline
\end{tabular}

Коэффициент коррелятивной вариации [5, 6] множества факторов физического объекта исследования (в общем случае), то есть биологического, химического, технологического, социально-экономического и пр., равен отношению общей суммы коэффициентов корреляции к квадрату от количества факторов.

В нашем примере коэффициент коррелятивной вариации соответственно будет равен 15,7597 / $4^{2}=15,7597 / 16=0,9850$. Это очень высокий показатель функциональной связности отдельных элементов СХУ.

Этот критерий применяется при сравнении различных объектов исследования, в данном случае земельных кадастров субъектов федерации и всей страны. При этом вид изучаемой системы не влияет на указанный критерий верификации, а коррелятивная вариация полностью зависит от внутренних свойств системы. Земельные ресурсы остаются в стране надежным источником.

Заключение. Статистическое моделирование позволяет выявить высокоадекватные тренды взаимной зависимости площади компонент сельхозугодий по общей формуле (1).

Идентификация общей модели (1) может быть выполнена по други категориям земельного кадастра не только России, но и субъектов федерации. При 
этом статистическое моделирование нужно проводить ежегодно, дополняя таблицу 1 новыми данными за последующие годы.

Результаты моделирования позволяют надеяться, что, наконец-то, будут приниматься осознанные повороты в земельной политике и в технологии землепользования, причем как по категориям земельного кадастра, так и по субъектам федерации. Высокая функциональная связность к этому обязывает.

Во всех моделях тренд получился в виде линейного уравнения из-за малого количества строк в таблице 1. Программная среда CurveExpert позволяет поместить табличные данные между двумя разными факторами до 3500 строк. Это позволяет в дальнейшем сельхозугодия рассматривать в разрезе всех субъектов федерации за какой-то один учетный год.

\section{Список литературы:}

1. Арзамасцев А.Д., Мазуркин П.М., Максимец Н.В. Факторный анализ сельскохозяйственного производства. Йошкар-Ола: МарГТУ, 2009. 388 с.

2. Государственный (национальный) доклад о состоянии и использовании земель в Российской Федерации в 2012 году. М.: Федеральная служба государственной регистрации, кадастра и картографии, 2013. 253 с.

3. Мазуркин П.М., Михайлова С.И. Биотехническая оценка пойменного луга. М.: Изд-во «Академия естествознания», 2009. 279 с.

4. Мазуркин П.М., Михайлова С.И. Модели кадастровой оценки сельхозугодий // АПК: Экономика и управление. 2009. № 8. С.76-82.

5. Мазуркин П. М., Михайлова С.И. Территориальное экологическое равновесие $=$ Territprial ecological balance: аналит. обзор; Учреждение Рос. акад. наук Гос. публич. науч.-техн. б-ка Сиб. отд-ния РАН. Новосибирск: ГПНТБ СО РАН, 2010. 430 с. (Сер. Экология. Вып. 94).

6. Михайлова С.И., Мазуркин П.М. Ландшафтно-экологическая роль пойменного луга малых рек. Йошкар-Ола: МарГТУ, 2011. 154 с. 